\title{
Disease Response Accepted Record Flag
}

National Cancer Institute

\section{Source}

National Cancer Institute. Disease Response Accepted Record Flag. NCI Thesaurus. Code C117387.

An indication or description of a record that is considered to be the accepted and final evaluation for the disease response. 